\title{
Physico-chemical, Functional, Nutritional Quality and Antioxidant Level of Indian Street Food: Samosa
}

\author{
Diksha and Rajni Modgil*
}

College of Home Science, CSKHPKV Palampur H.P. 176062 India

*Corresponding author

\section{A B S T R A C T}

\section{Keywords}

Samosa, Street foods, Calorific value, True protein, minerals, Peroxide value organoleptic evaluation, Antioxidants

\section{Article Info}

Accepted:

26 April 2020

Available Online:

10 May 2020
A samosa is a fried or baked dish with a savory filling. The present study was undertaken to evaluate street food Samosa...? It was evaluate for its physical, functional, nutritional quality, Antioxidant activity and peroxide value. An attempt was also made to do value addition of the same. Control samples were prepared in the laboratory, samples were also procured from the local street vendors and value addition was done by adding locally available food material. The samples were also evaluated for their organoleptic acceptability. A significant difference was there in the physical functional and nutritional quality of the samples procured from street vendors. Water absorption and oil absorption capacity was lowest in the street vendor sample. Value addition of Samosa resulted in an increase in the crude protein by $34.75 \%$ calorific value $2.13 \%$ and crude fiber 96 per cent. An increase of $7.21 \%$ was noted in the DPPH (Inhibition activity). Mineral viz., iron, calcium and phosphorous also increased after value addition where as $14.33 \%$ decrease in total carbohydrate content was there. . The peroxide, free fatty acid was less in the control and value added sample as compared to samples procured from street vendor. Acceptability of value added Samosa was higher as compared to control and samples procured from street vendor Value addition was helpful in improving the nutritional quality of street food.

\section{Introduction}

Changed life style has resulted changes in the food habits which might have been due to non-availability of the time and altered food habits of the society due to cultural interactions, hectic activities and more women joining the jobs which resulted in tendency to eat outside. Eating outside the house particularly fast foods also known as street foods is due to their easy availability during shortage of time. There are many street foods which are consumed by people but have not been explored nutritionally and samosa is also one of these. Samosa is a fried or baked dish with a savory filling, such as spiced potatoes, onions, peas, meat, or lentils. It may take different forms, including triangular, cone, or half-moon shapes, depending on the region. The recipe of Samosa originated in the Middle East and Central Asia. It then spread to Africa, Southeast Asia, South Asia, and elsewhere. The Samosa spread to the Indian subcontinent, alongside the spread of Islam, 
during Muslim rule in the region. The Samosa word is derived from Persian word sanbosag. It is popular snack food in India. Traditionally, Samosa is fried street food (Chapman, 2007; Sakhale et al., 2011). Work has not been reported on the nutritional, functional quality and organoleptic acceptability of Samosa and also on its value addition. In the present study an attempt has been made to analyze nutritional and functional quality of Samosa available with street vendor and then its value addition with locally available raw food material.

\section{Materials and Methods}

\section{Preparation of samples}

Samples of Samosa were procured from local street food vendors. Control and value added samples were prepared in the laboratory (Ingredients used are given in table 1). Figure 1 depicts the flow sheet for preparation of samosa. All samples were dried separately to make them moisture free by placing them into hot air oven at a temp. of $60^{\circ} \mathrm{C}$ for $8 \mathrm{hrs}$ and then grounded into a fine powder. Samples were stored in airtight glass jars till further analysis was completed. The prepared sample was evaluated for various physico-chemical characteristics, functional properties, proximate composition, nutritional and functional quality. All three samples were evaluated for their sensory acceptability by a panel of ten semi trained judges on nine point hedonic scale. All the analysis was done in triplicate.

\section{Physical characteristics}

Shape and Size were observed by visual perception. Weight in triplicate was measured on an electric scale. Length was measured using a measuring scale. Ten food sample of each street food street was taken. Thickness was taken at three different parts of samosa i.e. top central and lower part using a Vernier caliper.

Water Absorption and Oil absorption Capacity was analyzed by the method of Sosulski and Garratt (1976) and Lin et al., (1974) respectively.

Proximate constituents' viz. moisture, ash, crude protein, crude fat, crude fiber was determined by standard methods of AOAC (2010). Conversion factor of 6.25 was used to convert nitrogen into protein. Total carbohydrates were calculated by using method given by Gopalan et al., (2007).

\section{Nutritional composition}

The prepared samples were determined for their nutritional analysis viz., energy (O'shea and Maguire, 1962), starch (Clegg 1956), Non-protein nitrogen (Pellet and young 1980), true protein (Crude protein NitrogenNPN), reducing sugars, non-reducing sugars, total sugars (Yemn and Willis, 1954), ADF and NDF (Van Soest and Wine 1967), hemicellulose (NDF-ADF), peroxide value (AOAC, 1999), free fatty acids (AOCS, 1998), anti-oxidant activity (Miliauskas and Khalaf et al., 2004).

\section{Minerals}

Calcium, phosphorus were analyzed by method of Chen et al., 1956, iron and zinc were determined in the selected street foods. Determination of zinc and iron was done by using atomic absorption spectrophotometer, Model 3100, Perkin Elmer. Calcium was determined with the help of flame photometer, Mediflame, 127.

\section{Sensory evaluation}

The samples were evaluated organoleptically by the 10 panelist using a 9 point hedonic 
scale. The parameters on which the prepared products evaluated were color, taste, flavor, texture and overall acceptability. The index of acceptance (IA \%) was calculated using the following equation (Schumacher et al., 2010).Index of Acceptance $(\%)=\mathrm{M} / 9$ X100 Where $M$ indicates the average of the evaluations carried out by sensory panel.

All the data so obtained were subjected to Analysis of Variance (ANOVA) using OP stat software. The obtained data were interpreted at $5 \%$ level of significance $(p \leq 0.05)$.

\section{Results and Discussion}

\section{Physical and functional properties}

Table 2depicts the physical and functional properties i.e. colour, shape, weight, length, thickness and functional properties i.e. water absorption capacity and oil absorption capacity of samosa samples. Colour is defined as the property possessed by an object of producing different sensations on the eye as a result of the way it reflects or emits light. There was no difference in the colour and shape of the control, street vendor and value added samples which were golden brown in colour and had triangular shape. The golden brown color might have been due to the nonenzymatic browning during frying.

A body's relative mass or the quantity of matter contained by it, giving rise to a downward force or the heaviness of a thing is referred as weight. A non-significant difference was observed in the weight and length of the control, street vendor and value added samples of Samosa when compared with each other. The weight was 70.00, 76.25 and $72.25 \mathrm{~g}$, respectively. The length of the samples was $6.27,6.17$ and $6.68 \mathrm{~cm}$, respectively. There were a significant $(p \leq 0.05)$ difference observed in the thickness of three samples when compared with each other, values being2.00, 2.10 and 2.50 inch, respectively. The thickness was maximum in the value added samosa when compared with control and street vendor samples. There was a non-significant $(\mathrm{p} \leq 0.05)$ difference in the thickness of control and street vendor samples when compared with each other.

Water absorption capacity is the amount of water taken up by flour to achieve the desired consistency or optimal end result. Water absorption capacity of the control, street vendor and value added samples was 2.50, 2.34 and $5.07 \mathrm{ml} / \mathrm{g}$ respectively. There were a significantly $(\mathrm{p} \leq 0.05)$ higher water absorption capacity in value added samosa as compared to the control and street vendor samples. However the water absorption capacity of control and street vendor samples differed non-significantly $(\mathrm{p} \leq 0.05)$ from each other. The higher water absorption capacity in value added samosa might have been due to the presence of whole wheat flour in it because the existence of bran in whole wheat flour might have caused a significant increase in the water absorption capacity.

Oil absorption capacity shows a defined correlation with emulsifying capacity for most proteins making it possible to predict emulsifying capacity in a simple way. According to the data depicted in table 2, oil absorption capacity of control, street vendor and value added sample of samosa was 1.76 , 1.25 and $3.10 \mathrm{ml} / \mathrm{g}$ respectively. Oil absorption capacity was significantly $(\mathrm{p} \leq 0.05)$ higher in the value added samosa when compared with control and street vendor samples. The difference in oil absorption capacity in the samples might have been due to variation in the raw ingredients used for their preparation.

\section{Proximate composition}

Proximate composition is an important parameter for getting the information about the nutritional and biochemical quality of 
food. Major components of food item like moisture, ash, crude fat, crude fiber and crude protein content were included in the proximate composition. Table 3depicts that value addition resulted in an significant increase in crude ash, crude fiber, ether extract and crude protein content of samosa where as a significant decrease was reported in the moisture and total carbohydrates. The difference in proximate constituents might have been due to variation in raw ingredients. Difference in the moisture content of samples might have been due to the variation in the frying temperature as frying might have been initiated loss in moisture content of the samples.The higher ash and fiber content in value added samosa might have been due to alteration of refined flour which is used for making samosa sheet with whole wheat flour and rice flour. As the whole wheat flour and rice flour is found to have high ash content than refined wheat flour (Gopalan et al., 2007). Nago et al., (2009) reported that out of home prepared food, contributed more than 40 per cent of daily fiber intake of adolescents. Variation in raw material in value added samosa resulted in an increase in the nutritive value of the product

\section{Nutritional composition}

Table 4 depicts the nutritional composition of control, street vendor and value added samples of samosa. The NPN and content of value added samosa was none significantly $(p \leq 0.05)$ lower as compared to Samosa. procured from street vendorthe values being $0.01,0.07$ and 0.02 per cent for NPN and $44,72,40.65$ and 30.01 for starch content in control street vendor and value added samples respectively. This difference might have been due to variation in the method of processing and raw ingredients used. Refined wheat flour is found to have high starch content than the whole wheat flour, this is why samosa prepared with refined wheat flour i.e. control and procured from street vendor more likely to have high starch content than the value added samosa.

True protein, total sugars, reducing and nonreducing sugars, and all dietary fiber constituents were significantly $(\mathrm{p} \leq 0.05)$ increased after value addition (Table 4$)$. The maximum calorific content of value added samosa might have been due to its higher fat, protein and sugar content as compared to control and street vendor samosa.

The higher reducing sugars content in the value added sample might have been due to variant extent of carbohydrate hydrolysis during frying.

High dietary fiber constituent in the value added samosa might have been due to the contribution of fiber by the whole wheat flour and rice flour which are rich in bran found to have high fiber content than the refined flour.

\section{Peroxide value}

Detection of peroxide gives the initial evidence of rancidity in unsaturated fats and oils. The double bonds found in fats and oils play a role in autoxidation. Oils with a high degree of unsaturation are most susceptible to autoxidation. The best test for autoxidation (oxidative rancidity) is determination of the peroxide value. Peroxides are intermediates in the autoxidation reaction. There was a significant $(\mathrm{p} \leq 0.05)$ difference in the peroxide value and free fatty acid content of street vendor samosa when compared with control and value added samples of samosa. However, there was a non-significant difference in the peroxide value of control and value added sample when compared to each other. Peroxide value was maximum in the samples procured from street vendor when compared with the rest of the samples, which gives an indication about the use of oxidized 
oil by the street vendor. The higher peroxide value of street vendor sample might have been due to the reusing of oil for several number of times.

\section{DPPH}

It is a common abbreviation for the organic chemical compound 2,2-diphenyl-1picryhhydrazyl. It is a dark colored crystalline powder compared of stable free radical molecules. DPPH has two major applications, both in laboratory research: one is monitoring of chemical reactions involving radicals, most notably it is a common anti-oxidant essay, and another is a standard of the position and intensity of electron paramagnetic resonance signals.

Data depicted in table 4 shows that, per cent of DPPH in control, street vendor and value added sample of samosa was 53.33, 53.70 and 57.57. The DPPH value maximum in the value added samosa followed by samosa procured from street vendor and control. Fresh oils are found to have high antioxidant activity than the used one. The higher antioxidant activity of value added samosa might have been due to the use of fresh oil for frying.

\section{Macro and micro minerals}

Value addition of samosa resulted in an increase in macro and micro elements. The values of iron, zinc, calcium and phosphorus were significantly $(\mathrm{p} \leq 0.05)$ higher in value added samples. Values being iron3.53, 4.07 and $6.79 \mathrm{mg} / 100 \mathrm{~g}$, zinc1.00, 1.02 and 1.64 $\mathrm{mg} / 100 \mathrm{~g}$, calcium 18.92, 25.37 and 48.18 $\mathrm{mg} / 100 \mathrm{~g}$ and phosphorus 77.56, 83.97 and 188.02, respectively in control, street vendor and value added samples. The higher mineral content in value added samosa might have been due to higher iron, zinc, calcium and phosphorus content of whole wheat flour and rice flour than the refined flour (Gopalan et al., 2007).

\section{Sensory evaluation}

Sensory evaluation is defined as "a scientific discipline used to invoke, measure, analyze, and interpret reactions to characteristics of foods and materials as they are perceived by the senses of sight, smell, taste, touch, and hearing".. The organoleptic acceptability of control, street vendor and value added samples has been given in the figure 2 .

Table.1 Ingredients used for preparation of Samosa

\begin{tabular}{|c|c|c|}
\hline Ingredient & Control & Value added \\
\hline Refined flour & $100 \mathrm{~g}$ & - \\
\hline Whole wheat flour & - & $50 \mathrm{~g}$ \\
\hline Rice flour & - & $50 \mathrm{~g}$ \\
\hline Omum & $5 \mathrm{~g}$ & $5 \mathrm{~g}$ \\
\hline Onion & $25 \mathrm{~g}$ & $25 \mathrm{~g}$ \\
\hline Potatoes & $100 \mathrm{~g}$ & $100 \mathrm{~g}$ \\
\hline $\begin{array}{c}\text { Spices (green chilli, coriander seeds, } \\
\text { cumin seeds, red chilli powder, dried } \\
\text { fenugreek leaves, salt, })\end{array}$ & $2 \mathrm{~g}($ each) & $2 \mathrm{~g}($ each) \\
\hline Oil for frying & & \\
\hline
\end{tabular}


Table.2 Physical Characteristics, water absorption and oil absorption capacity of Samosa

\begin{tabular}{|l|c|c|c|c|}
\hline \multicolumn{1}{|c|}{ Parameters } & Control & Street vendor & Value Added & CD(P $\leq \mathbf{0 . 0 5})$ \\
\hline Colour & Golden Brown & Golden Brown & Golden Brown & - \\
\hline Shape & Triangular & Triangular & Triangular & - \\
\hline Weight $(\mathbf{g})$ & 70.00 & 76.25 & 72.25 & NS \\
\hline Length $(\mathbf{c m})$ & 6.27 & 6.17 & 6.68 & NS \\
\hline Thickness (inch) & 2.00 & 2.10 & 2.50 & 0.27 \\
\hline $\begin{array}{l}\text { Water Absorption } \\
\text { Capacity(ml/g) }\end{array}$ & 2.50 & 2.34 & 5.07 & 0.75 \\
\hline $\begin{array}{l}\text { Oil absorption } \\
\text { capacity }(\mathbf{m l} / \mathbf{g})\end{array}$ & 1.76 & 1.25 & 3.10 & 0.90 \\
\hline
\end{tabular}

Table.3 Proximate composition of control, street vendor and value added Samosa

\begin{tabular}{|l|c|c|c|c|}
\hline \multicolumn{1}{|c|}{ Parameters } & Control & $\begin{array}{c}\text { Street } \\
\text { vendor }\end{array}$ & Value Added & CD(P $\leq \mathbf{0 . 0 5})$ \\
\hline Moisture (\%) & 3.84 & 6.81 & 5.00 & 1.22 \\
\hline Crude Ash (\%) & 2.82 & 3.85 & 5.25 & 0.28 \\
\hline Crude Fiber (\%) & 1.72 & 1.16 & 2.28 & 0.18 \\
\hline Ether extract (\%) & 26.99 & 28.60 & 31.49 & NS \\
\hline Crude Protein (\%) & 7.58 & 9.36 & 12.61 & 2.08 \\
\hline Total Carbohydrates (\%) & 57.08 & 50.59 & 43.34 & 7.04 \\
\hline
\end{tabular}

Table.4 Nutritional composition, Peroxide value DPPH activity and mineral content of control, street vendor and value added Samosa

\begin{tabular}{|l|c|c|c|c|}
\hline \multicolumn{1}{|c|}{ Parameters } & Control & Street vendor & Value Added & CD(P $\leq \mathbf{0 . 0 5})$ \\
\hline NPN (\%) & 0.01 & 0.07 & 0.02 & NS \\
\hline True Protein (\%) & 7.51 & 8.92 & 12.48 & 2.49 \\
\hline Energy (Kcal/100g) & 501.16 & 497.28 & 507.29 & NS \\
\hline Starch (\%) & 44.72 & 40.65 & 30.01 & 11.51 \\
\hline Reducing sugars (\%) & 2.20 & 4.42 & 5.46 & 0.67 \\
\hline Non- reducing sugars (\%) & 4.86 & 5.89 & 7.37 & 1.91 \\
\hline Total Sugars (\%) & 7.06 & 9.91 & 12.83 & 1.76 \\
\hline ADF (\%) & 2.92 & 4.45 & 8.95 & 1.73 \\
\hline NDF (\%) & 20.50 & 28.50 & 36.07 & 6.00 \\
\hline Hemi- cellulose (\%) & 17.57 & 24.05 & 27.12 & 6.42 \\
\hline Peroxide value(meq/kg) & 2.57 & 11.64 & 3.18 & 1.31 \\
\hline FFA (\% Oleic acid) & 0.46 & 1.67 & 0.56 & 0.31 \\
\hline DPPH (\% inhibition) & 53.33 & 53.70 & 57.57 & 0.82 \\
\hline Iron (mg/100g) & 3.53 & 4.07 & 6.79 & 0.47 \\
\hline Zinc (mg/100g) & 1.00 & 1.02 & 1.64 & 0.05 \\
\hline Calcium (mg/100g) & 18.92 & 25.37 & 48.18 & 2.86 \\
\hline Phosphorus (mg/100g) & 77.56 & 83.97 & 188.02 & 4.74 \\
\hline
\end{tabular}


Fig.1 Flowchart for Preparation of Samosa

Weighing of flour, omum seeds and dried fenugreek leaves

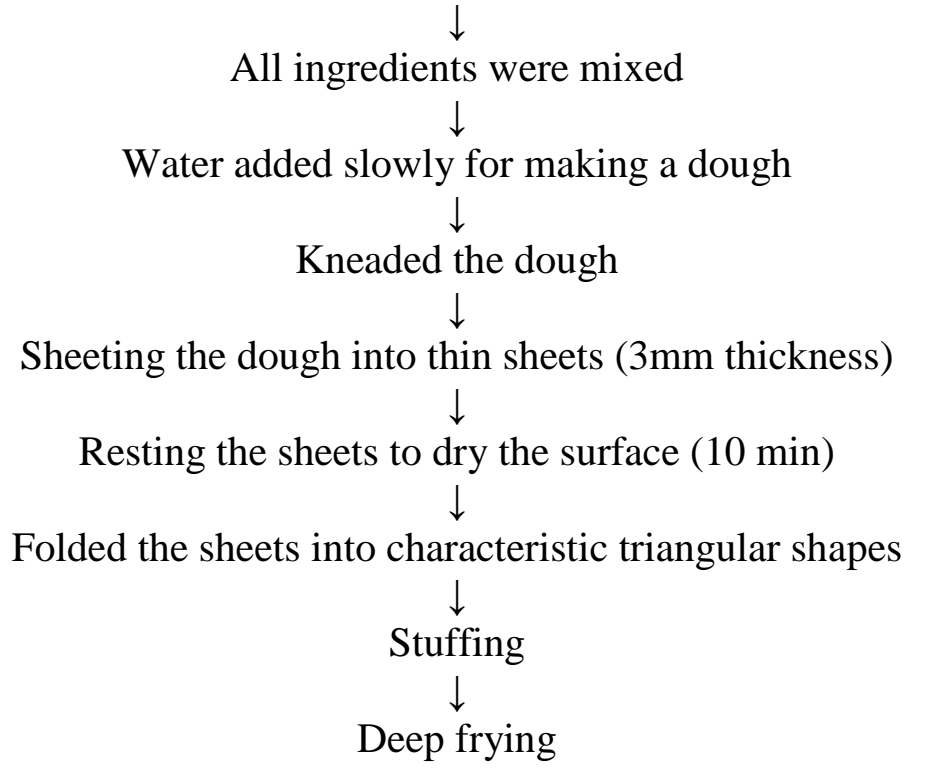

Figure.2 Organoleptic Evaluation of Control, street vendor and value added samples of Samosa

\begin{tabular}{|c|c|c|c|c|c|}
\hline \multicolumn{6}{|c|}{ Fioure? } \\
\hline \multicolumn{6}{|l|}{20} \\
\hline \multicolumn{6}{|l|}{15} \\
\hline \multicolumn{6}{|l|}{10} \\
\hline \multicolumn{6}{|l|}{5} \\
\hline \multirow[t]{2}{*}{0} & & & & & \\
\hline & Colour & Taste & Flavour & Texture & $\begin{array}{c}\text { Acceptab } \\
\text { ility }\end{array}$ \\
\hline $\mathrm{CD}(\mathrm{p} \leq 0.05)$ & 0.65 & 0.58 & 0.67 & 0.64 & 0.54 \\
\hline Value added & 7.59 & 7.39 & 7.33 & 7.59 & 7.49 \\
\hline Street Vendor & 7.52 & 7.11 & 7.03 & 7.15 & 7.21 \\
\hline Control & 7.33 & 6.82 & 6.47 & 6.69 & 6.91 \\
\hline
\end{tabular}

Control Street Vendor $\quad$ Value added $\quad \mathrm{CD}(\mathrm{p} \leq 0.05)$ 
The sensory scores for color, taste, and flavor and texture parameter were significantly higher for value added samosa as compared to sample procured from street vendor as well as controlled samples. This might have been due to the enrichment of value added samosa covering with rice flour which helped in providing the significant $(\mathrm{p} \leq 0.05)$ change of color in value added samosa. The higher taste score of value added sample might have been due to variation in the raw ingredient used for making value added samosa than the control and street vendor sample.

The higher scores for texture was in value added samosa this might have been due to the addition of rice flour for making the covering of value added samosa made it crispier and caused a desirable texture change than the rest of the samples. The overall acceptability scores for control, street vendor and value added samples was 6.91, 7.21 and 7.49 respectively. A non- significant difference $(p \leq 0.05)$ was observed in the overall acceptability score of street vendor sample when compared with control and street vendor samples. However the difference in the overall acceptability score of control and value added sample was significant $(p \leq 0.05)$. Overall acceptability score was maximum for the value added sample of samosa than the rest of the samples of samosa.

From the present study, it can be concluded that the nutritive value of these foods can be increased by value addition, which can be done by replacing the outer covering of samosa with whole wheat flour and rice flour in the ratio 50:50. Value addition with agricultural crops can be helpful in improving the nutritional quality of street foods.

\section{References}

AOAC. 2010. Official methods of analysis. Association of Official Analytical Chemist, Washington D.C.UK.14.068,
2057

AOAC. 1999. Official methods of analysis, Association of Official Analytical Chemists, Washington

AOCS. 1998. Official Method for analysis. American Oil Chemists' Society (5). Journal of Food Composition and Analysis 18(2):171-179

Chapman P .2007. India: Food and Cooking. New Holland publication (UK), Ltd, London. p84

Chen PS, Tosibora TY and Warner H. 1956. Micro determination of phosphorus. Analytical Chemistry 28: 1756 - 1759

Clegg KM. 1956. The application of the anthrone reagent to the estimation of starch in cereals. Journal of Food Science and Agriculture 7(1):40

Gopalan C, Rama Sastri BV, Balasubramanian SC. 2007. Nutritive value of Indian foods 59-77

Khalaf AN, Shakya AK, Othman AL, ELAgbar Z, Faran H.2008. Antioxidant activity of some common plants. Turkish Journal of Biology 32: 51-55

Lin MJY, Humbert ES and Sosulski FW. 1974. Certain functional properties of sunflower meal products. International Journal of Food Science and Technology 39: 368-370.

Miliaukas GP, Venskutonis RP and Beek TA.2004. Screening of radical scavenging activity of some medicinal and aromatic plant extracts. Food Chemistry 85(2):231-237

O'shea JO and Maguire MP. 1962. Determination of calorific value of food stuff by chromic acid oxidation. Journal of the Science of Food and Agriculture 13: 530-532

Pellet LP and Young VR. 1980. Nutritional evaluation of protein food. UN University Publication. p 257

Sakhale BK, Badgujar JB, Pawar VD andSananse SL (2011). Effect of hydrocolloids incorporation in casing of 
samosa on reduction of oil uptake. Journal of Food Science and Technology, 48(6):769-772

Sezgin CA., and Şanlier N. 2016. Street food consumption in terms of the food safety and health. Journal of Human Sciences 13(3), 4072-4083.

Sosulski FW, Garatt MO, Slinkard AE. 1976. Functional properties of ten legume flours. International Journal of Food
Science and Technology 9:66-69.

Van Soest PJ and Wine RH. 1967. Use of detergent in the analysis of fibrous foods, determination of plant cell wall constituents. Journal of Association of Official Analytical Chemistry 50: 50

Yemn EC and Willis AJ .1954.The estimation of carbohydrates in plant extracts by anthrone. Biochemical Journal 57: 508514.

\section{How to cite this article:}

Diksha and Rajni Modgil. 2020. Physico-chemical, Functional, Nutritional Quality and Antioxidant Level of Indian Street Food: Samosa. Int.J.Curr.Microbiol.App.Sci. 9(05): 35223530. doi: https://doi.org/10.20546/ijcmas.2020.905.419 